\title{
Relationship of serum ionized calcium and magnesium concentration with parasympathetic nerve Function in type 2 diabetes mellitus
}

\author{
Md. Khairul Alam ${ }^{1}$, Noorzahan Begum², Shelina Begum ${ }^{3}$
}

\begin{abstract}
Background: Changes in serum $\mathrm{Ca}^{2+}$ and $\mathrm{Mg}^{2+}$ level may have some relationship to the occurrence of autonomic neuropathy in diabetes. Objective: To observe relationship between parasympathetic nerve function and serum ionized calcium \& magnesium in type 2 diabetes mellitus (T2DM). Methods: This cross sectional study was carried out in the Department of Physiology, Bangabandhu Sheikh Mujib Medical University (BSMMU), Dhaka on 47 T2DM patients aged 40-68 years of both sexes. Twenty five patients were recently diagnosed diabetics (RDM) and 22 were long term diabetics (LDM) with 10-20 years duration of diabetes. Parasympathetic nerve functions of all patients were assessed by three simple non-invasive cardiovascular reflex tests. Ionized serum calcium and magnesium were measured by ion sensitive electrode method using NOVA electrode. Data were analyzed by unpaired' $t$ 'test and Pearson's correlation co-efficient test. Results: Serum ionized calcium and magnesium levels were significantly higher in RDM $(\mathrm{P}<0.001)$ and LDM $(\mathrm{P}<0.001)$ compared to healthy control. On correlation analysis, significant negative correlation of parasympathetic nerve function with $\mathrm{Mg}^{2+}$ was found in both RDM and LDM patients. Conclusion: The result of this study concluded that higher calcium and magnesium ion may be associated with type 2 diabetes and parasympathetic nerve function of diabetic patients may have inverse relationship to serum $\mathrm{Mg}^{2+}$.
\end{abstract}

Key words: Parasympathetic, neuropathy, diabetes, nerve.

\author{
J Bangladesh Soc Physiol. 2016, December; 11(2): 70-73 \\ For Authors Affiliation, see end of text. \\ http://www.banglajol.info/index.php/JBSP
}

\section{Introduction}

C

alcium and magnesium play a key role in cellular metabolism. In vitro studies

have shown magnesium as second messenger for insulin action. ${ }^{1,2}$ Intracellular free calcium was found elevated and magnesium was deficient in type 2 diabetic subjects. ${ }^{1,3,4,5}$ In a Nigerian study, low fasting plasma magnesium were found associated with increased urinary excretion in diabetics which indicate its poor metabolic control. 5,6

Received 20th March 2016; Accepted 4th Aug. 2016
The possible relationship of $\mathrm{Ca}^{2+}-\mathrm{Mg}^{2+}$ - ATPase activity and serum ionized calcium in diabetic patients with peripheral neuropathy have been investigated. Migdalis et al. also reported that there are abnormalities of $\mathrm{Ca}^{2+}-\mathrm{Mg}^{2+}$ ATPase activity and serum $\mathrm{Ca}^{2+}$ in patients with diabetic neuropathy ${ }^{7}$.

Various in vitro and vivo studies have demonstrated that insulin increases the cellular uptake of magnesium. Intracellular $\mathrm{Mg}^{2+}$ concentration plays effective role in modulating insulin action (mainly oxidative glucose 
metabolism), calcium related excitationcontraction coupling, which in turn decrease smooth muscle cell responsiveness to stimuli. Again, poor intracellular magnesium concentration, may result in a defective tyrosine activity at the insulin receptor level and increased intracellular calcium ion concentration. ${ }^{4,5}, 8,9$

As diabetes mellitus is associated with disturbances of different metabolic processes of all tissues including electrolyte imbalance. Therefore, changes in serum level of some of the electrolytes e.g. serum calcium and magnesium may have some relationship to the occurrence of neuropathy. ${ }^{5,7}$ In our country a large member of diabetic patients are suffering from neuropathy. Among them a quiet large member may have diabetic cardiac autonomic neuropathy which remains undetected unless complicated. Cardiac autonomic neuropathy is the clinically important form of diabetic autonomic neuropathy. ${ }^{6}$ Again, severity of cardiac autonomic neuropathy depends on the metabolic derangement. ${ }^{5}$ In addition, serum $\mathrm{Ca}^{2+}$ and $\mathrm{Mg}^{2+}$ may have some contribution in the development of cardiac autonomic dysfunction in patients with type 2 diabetes mellitus.

In the above context, this study aimed to observe the relationship of parasympathetic nerve function parameters with serum $\mathrm{Ca}^{2+}$ and $\mathrm{Mg}^{2+}$ in type 2 diabetes patients.

\section{Method}

This cross sectional study was carried out in the Department of Physiology, Bangabandhu Sheikh Mujib Medical University (BSMMU) from $1^{\text {st }}$ July 2003 to $30^{\text {th }}$ June 2004, Dhaka. The protocol of the study was approved by Departmental Ethical Committee of Department of Physiology of BSMMU. For this study 47 type 2 diabetic patients both male and female with age range 4068 years were enrolled from out-patient department (OPD) of BIRDEM, Dhaka. Among them 25 patients were recently diagnosed diabetics (RDM) and 22 were long term diabetics
(LDM) with 10-20 years duration of diabetes. After selection of the subjects, the nature, purpose and benefit of the study were explained to each subject in details and informed written consent was taken. All the subjects were free from acute diabetic complications, pregnancy, renal failure, under systemic steroid therapy and other acute and chronic illnesses. Before taking blood, detailed family and medical history were taken. All the information was recorded in a data schedule. Fasting blood samples were collected in the morning after 10-16 hours of overnight fast for estimation of serum levels of FPG, creatinine, ionized calcium and ionized magnesium and then parasympathetic nerve functions tests were done on the same day. Estimation of all the biochemical tests were done Biomedical Research Group Laboratory, BIRDEM and Valsalva, deep breathing test and lying to standing tests were done to assess parasympathetic function. in autonomic nerve function laboratory of the physiology Department, BSMMU, Dhaka ${ }^{10}$. Serum glucose was estimated by glucose oxidase (GOD/PAP) method (Bio-labofrance). Serum creatinine was measured by Alkaline Picrate method (Ramdox laboratories, UK). Ionized serum calcium and magnesium were measured by ion sensitive electrode method using NOVA electrode (Chronelab, USA). For statistical analysis, unpaired t test and Pearson's correlation coefficient test were done. $\mathrm{P}<0.05$ were taken as level of statistical significance.

\section{Results}

Anthropometric results are shown in Table I. Serum ionized calcium levels were significantly higher in both group of patients $(\mathrm{P}<0.001)$ compared to healthy subjects but serum ionized magnesium level was significantly higher only in LDM patients compared to control. No significant difference was found in respect of both ionized calcium and magnesium between LDM and RDM. (Table II) Relationship of parasympathetic nerve function parameters with 
ionized calcium level were shown in Table III. Valsalva ratio, Deep breathing, $30^{\text {th }}: 15^{\text {th }}$ ratio were negatively correlated with serum $\mathrm{Ca}^{2+}$ in RDM whereas positively correlated with serum $\mathrm{Ca}^{2+}$ in LDM except $30^{\text {th }}: 15^{\text {th }}$ ratio were negatively correlated in LDM. None of the correlations were statistically significant. Relationship of parasympathetic nerve function parameters with ionized magnesium level were shown in table IV. Valsalva ratio showed significant negative correlation with serum $\mathrm{Mg}^{2+}$ in RDM only but deep breathing showed significant negative correlation in LDM only. $30^{\text {th }}: 15^{\text {th }}$ did not show any significant correlation with serum $\mathrm{Mg}^{2+}$ in both RDM and LDM.

Table I: Baseline characteristic of all subjects $(n=72)$

\begin{tabular}{lccc}
\hline Parameters & Control $(\mathrm{n}=25)$ & RDM $(\mathrm{n}=25)$ & LDM $(\mathrm{n}=22)$ \\
\hline Age $($ years $)$ & $51.92 \pm 1.12$ & $51.52 \pm 1.38$ & $55.77 \pm 1.23$ \\
BMI $\left(\mathrm{kg} / \mathrm{m}^{2}\right)$ & $25.28 \pm 0.59$ & $24.58 \pm 0.49$ & $24.47 \pm 0.58$ \\
\hline
\end{tabular}

Data presented as mean \pm SE. Unpaired $t$ test was done for statistical analysis. BMI $=$ Body mass index. Control= Healthy subjects. RDM= Recently diagnosed T2DM, LDM=T2DM for 10-20 years; T2DM=Type 2 diabetes mellitus.

Table II: Serum ionized calcium and magnesium levels in different study group(n=72)

\begin{tabular}{lccc}
\hline Parameters & Control $(\mathrm{n}=25)$ & RDM $(\mathrm{n}=25)$ & LDM $(\mathrm{n}=22)$ \\
\hline Serum $\mathrm{Ca}^{+}(\mathrm{mmol} / \mathrm{L})$ & $0.93 \pm 0.10$ & $1.04 \pm 0.10^{*}$ & $1.10 \pm 0.10^{* *}$ \\
Serum $\mathrm{Mg}^{2+}(\mathrm{mmol} / \mathrm{L})$ & $0.49 \pm 0.05$ & $0.53 \pm 0.05)$ & $0.66 \pm 0.08^{*}$ \\
\hline
\end{tabular}

Data presented as mean \pm SE. Unpaired $t$ test was done for statistical analysis. Control= Healthy subjects, $\mathrm{RDM}=$ Recently diagnosed T2DM, LDM=T2DM for 10-20 years; T2DM= Type 2 diabetes mellitus. ${ }^{*} \mathrm{P}<0.05 * * \mathrm{P}<0.01$

Table III: Relationship of parasympathetic nerve function parameters with $\mathrm{Ca}^{2+}$ with different study group $(\mathrm{n}=72)$

\begin{tabular}{lc}
\hline Parameters & r value \\
\hline Valsalva ratio & \\
RDM & -0.038 \\
LDM & +0.122 \\
HR response to Deep breathing & \\
RDM & -0.019 \\
LDM & +0.070 \\
$30^{\text {th:15 }}{ }^{\text {th }}$ HR ratio & \\
RDM & -0.269 \\
LDM & -0.095 \\
\hline RDM = Recently Diagnosed T2DM, LDM \\
$=$ T2DM for 10-20 years.
\end{tabular}

Table IV: Relationship between parasympathetic nerve function parameters in $\mathrm{Mg}^{2+}$ in different study group $(\mathrm{N}=72)$

\begin{tabular}{lc}
\hline Parameters & r value \\
\hline Valsalva ratio & $-0.483^{*}$ \\
RDM & -0.217 \\
LDM & \\
HR response to deep breathing & -0.338 \\
RDM & $-0.474^{*}$ \\
LDM & \\
$30^{\text {th }}: 15^{\text {th }}$ HR ratio & -0.020 \\
RDM & -0.224 \\
LDM & \\
\hline RDM = Recently diagnosed T2DM, LDM=T2DM for \\
$10-20$ years. $*$ P Ầ 0.05.
\end{tabular}




\section{Discussion}

The present study has been undertaken to observe serum ionized calcium and magnesium and their relationship with parasympathetic nerve function parameters in T2DM patients.

In this study, serum ionized calcium level was found significantly higher in RDM and LDM. However, no statistically significant change in serum calcium level was found between two diabetic groups. Migdalis et al. ${ }^{7}$ reported lower level of serum ionized calcium in diabetic neuropathic subjects. Serum ionized magnesium level was significantly higher in LDM only. No statistically significant higher value of serum ionized magnesium level was observed in RDM. Similar higher level of serum ionized magnesium was also reported by Mikhail and Ehsanipoor but they did not mentioned about the duration of diabetes ${ }^{8}$. Correlation analysis between serum ionized calcium level with parasympathetic nerve function parameters were observed and none of the relationships were found to be statistically significant in diabetic patients. In this study relationship between ionized magnesium with parasympathetic nerve function test parameters were also observed. Among these, significant negative correlation were observed in valsalva ratio in RDM and HR in deep breathing test in LDM. No significant correlations were observed in others parasympathetic nerve function parameters with serum ionized magnesium concentration.

It has been suggested that lower level of serum ionized calcium and lower level of serum $\mathrm{Ca}^{++}$. $\mathrm{Mg}^{++}$- ATPase are usually associated with microangiopathy which may had some role in the pathogenesis of neuropathy. ${ }^{7}$

But the results of this study suggest that serum serum $\mathrm{Ca}^{++}-\mathrm{Mg}^{++}$were increased in diabetic patients with long duration and increased $\mathrm{Mg}^{++}$ was correlated to low parasympathetic nerve function in long term $\mathrm{T} 2$ diabetic patients.

\section{Conclusion}

The result of this study concluded that increased calcium and magnesium may be associated with type 2 diabetes mellitus and parasympathetic nerve function of long term diabetic patients may have inverse relationship to serum $\mathrm{Mg}^{2+}$.

\section{Conflict of Interest: None}

\section{Author affiliations}

*1. Md. Khairul Alam, Professor \& Head, Department of Physiology, Army Medical College Comilla. Email: dr.khairulalam@gmail.com.

2. Noorzahan Begum, Professor, Department of Physiology, Bangabandhu Sheikh Mujib Medical University, Dhaka. Email: noorzahan52@gmail.com.

3. Shelina Begum, Professor \& Chairman, Department of Physiology, Bangabandhu Sheikh Mujib Medical University, Dhaka.

*For Correspondance

\section{References}

1. Paslisso G, Sgambato S, Passariello N. Magnesium and glucose homeostasis. Diabetologica 1990; 33: 511-4.

2. Tonyai S, Motto C, Rayssiguer Y, Heaton FW. Erythrocyte membrane in magnesium deficiency. Am J Nutr 1985; 4: 399.

3. Resnick LM. Cellular calcium and magnesium metabolism in the pathophysiology and treatment of hypertension and related metabolic disorder. Am J Med 1992; 93: 118-208.

4. Olukoga AO, Erasmus RT, Adewaye HO. Erythrocyte and plasma magnesium status in Nigerian with diabetes mellitus. Am Clin Biochem 1989; 26:74-77.

5. Smith RG, Heise CC, King JC. Serum and urinary magnesium, calcium and copper levels in insulin dependent diabetic women. J Trace Elem Electrolyte Health Dis 1988; 2: 239 - 43.

6. Pun KK, Ho PW. Subclinical hyponatremia, hyperkalemia and hypomagnesemia in patients with poorly controlled diabetes mellitus. Diabetes Res Clin Pract 1989; 7: 163 -7.

7. Migdahis IN, Xenos K, Chairopoulos K. $\mathrm{Ca}^{2+}-\mathrm{Mg}^{2+}$ ATPase activity and ionized calcium in type 2 diabetic patients with neuropathy. Diabetes Res Clin Pract 2000; 49(2-3): 113-8.

8. Mikhail $\mathrm{N}$ and Ehsanipoor K. Ionized serum magnesium in type 2 diabetes mellitus: It's correlation with total serum magnesium and hemoglobin $\mathrm{A}_{1 \mathrm{C}}$ levels. Southern Med J 1999; 92(12): 1162-6.

9. Barbagallo M, Dominguz LJ, Galioto A, Forlisi A, Canic C, Malfa L, Pineo A, Paolissog B. Role of magnesium in insulin action, diabetes and cardiometabolic syndrome X. Mol Aspeots Med. 2003; 24(13): 39-52.

10. Bannister R, Mathias CJ. Investigation of autonomic disorder. A test book of clinical disorders of the autonomic nervous system. $3^{\text {rd }}$ ed. United states: Oxford University Press; 1992 p. 255-89. 